\title{
Correction to: Gay and Bisexual Men's Perceptions of Pre-exposure Prophylaxis (PrEP) in a Context of High Accessibility: An Australian Qualitative Study
}

\author{
Steven Philpot ${ }^{1}$ (D) Garrett Prestage ${ }^{1} \cdot$ Martin Holt $^{2} \cdot$ Bridget Haire $^{1} \cdot$ Lisa Maher $^{1} \cdot$ Mohamed A. Hammoud $^{1}$. \\ Adam Bourne $^{3}$
}

Published online: 24 March 2020

(c) Springer Science+Business Media, LLC, part of Springer Nature 2020

\section{Correction to: AIDS and Behavior https://doi.org/10.1007/s10461-020-02796-3}

The original version of this article unfortunately contained an error. The authors would like to correct the error with this erratum.

In the original publication of the article, the given name of the 6th author was not correct. The name has been corrected with this erratum.

Publisher's Note Springer Nature remains neutral with regard to jurisdictional claims in published maps and institutional affiliations.

The original article can be found online at https://doi.org/10.1007/ s10461-020-02796-3.

Steven Philpot

sphilpot@kirby.unsw.edu.au

1 The Kirby Institute, UNSW Sydney, Level 6, Wallace Wurth Building, Kensington, NSW 2052, Australia

2 Centre for Social Research in Health, UNSW Sydney, Kensington, NSW 2052, Australia

3 Australian Research Centre in Sex, Health \& Society, La Trobe University, Melbourne, Australia 